\title{
CIGB-128, as compassionate intracranial treatment in patients with non-operable or progressive high grade gliomas
}

Garcia-Vega Yanelda1', Salva-Camaño Silvia², García-Iglesias Elizeth¹, Cubero-Rego David³, González-Gonzalez Justo and Bello-Rivero Iraldo ${ }^{1, *}$

\footnotetext{
${ }^{1}$ Clinical Research Department, Center for Genetic Engineering and Biotechnology (CIGB), Havana, Cuba

2 Clinic Surgical Hospital "Hermanos Ameijeiras" (HHA), San Lazaro, 701, CP10300, Centro Habana, Cuba

3 Pathology Department, Clinic Surgical Hospital "Hermanos Ameijeiras" (HHA), San Lazaro701, CP10300, Centro Habana, Cuba

${ }^{4}$ Neurosurgical Department, Clinic Surgical Hospital "Hermanos Ameijeiras" (HHA), San Lazaro701, CP10300, Centro Habana, Cuba
}

\begin{abstract}
Background: High grade glioma (HGG) is the most aggressive and lethal primary brain tumor. The treatment of patients with HGG still remains palliative with improvement in the quality of life and encompasses surgery, radiotherapy, and chemotherapy. The use of interferons (IFNs) in the treatment of HGG has been showed useful for these patients. Patients and methods: We report the use, outside of clinical trials, of recombinant IFNs- $\alpha$ and $\gamma$ (CIGB-128) in 10 patients with glioma grade III-IV (1 anaplastic astrocytoma and 9 GBM). The aim of the study was to offer a treatment option to patients with malignant gliomas, primary (non-surgical) or progressive (Karnofsky performance status $($ KPS) $>20$ ), without other possible therapeutic options, and non-eligible for clinical trials. Patients received intralesional CIGB-128, 3 times per week, during one month, in doses from 3.5 MIU scalable up to $14.0 \mathrm{MIU}$. Safety was evaluated by the occurrence of adverse events. Others measurements were tumor responses measured by RECIST, KPS muscular power (ASIA neurological assessment scale) and overall survival. Depending of treatment tolerability, clinical improvement and medical criteria, patients were maintained under treatment for 3 more months. Results: $70 \%$ of treated patients had KS $<50$. Seven patients had objective response (3 CR, 4 PR), one lesion progressed and 2 were not evaluable. The treatment prolonged the survival of patients to a mean of $34 \pm 14$ months since diagnosis. The quality of life improved as measured by the increase in the KPS (66\% of patients scaled the category) and improvement in muscular power in $50 \%$ of patients. CIGB-128 had an acceptable safety profile with fever as the most frequent adverse event, observed in $54.7 \%$, followed by extrapyramidal symptoms and hypopotassemia in $14.2 \%$ of treated patients. All detected adverse events were reversible. There was no evidence of cumulative hematologic toxicity. Conclusions: CIGB-128 demonstrated signs of clinical improvement, with an acceptable safety profile and measurable improvement in quality of life in patients with non-operable or progressive highgrade glioma. The use of this drug should be explored further in clinical trials with a larger number of patients to confirm these encouraging results.
\end{abstract}

Keywords: intracranial treatment; glioblastoma multiform; primary brain tumor

\section{Introduction}

IFNs are a family of natural multifunctional glycoproteins with a multitude of antitumor effects including inhibition of cell proliferation, induction of cell differentiation, upregulation of class I major histocompatibility complex antigens, inhibition of angiogenesis, and establishment of a T-helper 1 (Th1) type response [1, 2].

IFN- $\alpha$ sensitizes human malignant glioma cells to CD95Linduced apoptosis [3] down-regulates the expression of the proangiogenic molecules, such as basic fibroblast growth factor (bFGF), IL-8, and matrix metalloproteinase (MMP)-2 and -9 and inhibits the motility of vascular endothelial cells in vitro and angiogenesis in vivo [4].

IFN- $\gamma$ has strong anti-proliferative effects in glioblastoma cell lines and in vivo glioma cells expression of IFN- $\gamma$ result in a significant inhibition of tumor growth $[5,6]$. IFN- $\gamma$ upregulates several mediators of apoptosis in astrocitomas cells, such as Fas and TRAIL, as well as caspases-1, -4 and -7 [7] and stimulates the expression of PTEN and the NF $\kappa B$ transcriptional activity eliciting apoptosis in glioblastoma tumor cells with or without PTEN mutations [8, 9]. Additionally, IFN- $\gamma$ mediates anti-angiogenic action $[10,11]$, likely through the induction of angiostatic chemokine as

*Corresponding author: Iraldo Bello-Rivero, Clinical Research Department, Center for Genetic Engineering and Biotechnology (CIGB), Havana, Cuba. Email: iraldo.bello@cigb.edu.cu

Received 19 August 2015 Revised 29 October 2015 Accepted 12 November 2015 Published 25 November 2015

Citation: Garcia-Vega Y, Salva-Camaño S, García-Iglesias E, Cubero-Rego D, González-Gonzalez J, Bello-Rivero I. CIGB-128, as compassionate intracrania treatment in patients with non-operable or progressive high grade gliomas. J Cancer Res Ther. 2015; 3(11):136-143. DOI:10.14312/2052-4994.2015-20

Copyright: (c) 2015 Garcia-Vega Y, et al. Published by NobleResearch Publishers. This is an open-access article distributed under the terms of the Creative Commons Attribution License, which permits unrestricted use, distribution and reproduction in any medium, provided the original author and source are credited. 
IP-10 and the interaction with tumor micro-environment including endothelia cells [12]. This cytokine suppress proangiogenic action of VEGF [13]. Moreover, IFN- $\gamma$ as potent immunomodulator enhances the expression of MHC-I and -II antigens in glioma tumor cells, and infiltration of tumors by CD4+ and CD8+ T cells, contributing to elimination of tumor and prolongation of survival of animal bearing glioma tumors $[14,15]$. IFN- $\gamma$ may be a potential therapeutic agent for inducing the terminal differentiation of glioma-initiating cells (GICs) [15].

Malignant glioma is the most common brain tumor in adults, and the outcome of patients remains poor. The standard of care for adult patients with glioblastoma is radiation and temozolomide [16]. However, this regimen yields median survival times of only 12 to 15 months for patients with newly diagnosed glioblastomas and only 2 to 5 years for patients with newly diagnosed anaplastic gliomas [17].

For patients older than 70 years, less aggressive therapy is sometimes employed, using radiation or temozolomide alone [18]. However, clinical outcomes depend on the O-(6)-methylguanine-DNA methyltransferase (MGMT) status [19]. Additionally, GICs can self-renew and induce the formation of heterogeneously differentiated tumor cells and are resistant to chemotherapeutic agents like temozolomide $[20,21]$. Therefore, the search for new agents and innovative approaches for this disease is important.

Gliomas are highly vascularized tumors [22] with extremely elevated levels of numerous proangiogenic factors [2325]. Inhibiting the sprouting of new capillaries from preexisting blood vessels is one of the most promising therapeutic approaches for gliomas. The anti-angiogenic agent bevacizumab was approved by the U.S. Food and Drug Administration for recurrent glioblastoma [26]. When used with irinotecan, bevacizumab improved 6 month survival in recurrent glioma patients to $46 \%$ compared with $21 \%$ in patients treated with temozolomide [27, 28]. Anti-angiogenic agents also decrease peritumoral edema, potentially reducing the necessary corticosteroid dose.

The combination of IFNs $-\alpha$ and $-\gamma($ CIGB-128) has showed encouraging clinical and safety results in patients with advanced, recurrent, and resistant to previous treatment non-melanoma skin cancer [29].

Synergistic effects of combined treatment with IFN- $\alpha$ and $-\gamma$ have been noted [30]. The cooperative induction of cytokine-specific transcription factors is one mechanism for producing reinforcing effects of distinct cell-surface ligands while still maintaining the specificities of the individual inducers [30]. Therefore, the clear anti-angiogenic effects of both IFNs, in the context of the wide specter of biological activities shared by both cytokines could contribute to a more efficacious resolution of this difficult to treat lethal brain tumors.

With particular regard to malignant glioma, the use of immunomodulatory cytokines must also take into account the partial immune privileged status of the central nervous system and the documented ability of brain tumors to actively suppress host immune function [31]. There has, therefore, been increased interest in developing locoregional cytokine delivery paradigms for brain tumors, which are able to circumvent and/or undermine the physiochemical barriers to immune access associated with glioma.

The aim of the study was to offer a treatment option based in the combination of IFNs alpha $2 \mathrm{~b}$ and gamma, to patients with malignant glioma at end-of-life phase and to evaluate the safety and clinical benefit of the treatment.

\section{Material and methods}

\section{Patient characteristics}

Inclusion criteria: Patients, both genders, eligible for enrollment were 18 years of age or older, with histology proven high grade glioma, progressive after surgery or stereotactic biopsy, according to World Health Organization (WHO) criteria [32]; and a KS>20 were included.

Exclusion criteria: Patients with allergy to IFNs, decompensate seizure, signs of medullar depression, chronic decompensate diseases, hematological or metabolic compromised patients, were excluded.

The characteristics of the population of patients with GBM and $A A$ are shown in Table 1. Ten patients with progressive malignant gliomas (4 men and 6 women; median age, 59.4 years; age range, 32 to 72 years, median bodysurface $1.75 \mathrm{~m}^{2}$ ) were entered in the study after they or representing family gave informed consent in accordance with the guidelines of the Institutional Review Board. Previous treatments of patients are summarized in tables 2 and 3. Four percent of patients referred concurrent disease, predominantly arterial hypertension (30\%). Surgical resection in all cases was incomplete. Three patients had a KPS between 20-40, 5 patients between 50-60 and 1 patient over 70 .

Table 1 General baseline patient characteristics.

\begin{tabular}{lcc}
\hline & Characteristics & $N=10$ \\
\hline Sex & Males & $4(40 \%)$ \\
& Females & $6(60 \%)$ \\
Race & White & $8(80 \%)$ \\
& Non White & $2(20 \%)$ \\
Age categorized (years) & $<60$ & $4(40 \%)$ \\
& $\geq 60$ & $6(60 \%)$ \\
Age (years) & Median (range) & $59(32-72)$
\end{tabular}

\section{Treatment of patients}

A compassionate (outside of clinical trials) case treatment was conducted. The treatments were indicated to palliate the deteriorated clinical conditions of patients. Data about the safety and clinical benefit of intracranial application of this new pharmaceutical formulation containing IFNs $-\alpha$ and $-\gamma$ were recorded. Overall survival; objective response rate and palliative benefit in terms of improvement in KS scores and ASIA scale were also recorded. 
Table 2 Individual baseline patient's characteristics.

\begin{tabular}{|c|c|c|c|c|c|}
\hline Code & Age (years) & $\operatorname{Sex}$ & Race & Diagnostic & Previous treatments \\
\hline HA01 & 67 & M & NW & Multicentric GBM & Surgery \\
\hline HA03 & 64 & $\mathrm{~F}$ & W & GBM (cross middle line) & Surgery \\
\hline $\mathrm{HAO4}$ & 58 & $\mathrm{~F}$ & W & Deep GBM & Stereotactic biopsy \\
\hline HA05 & 72 & M & W & Deep occipital GBM & Stereotactic biopsy \\
\hline HA06 & 56 & M & NW & GBM & Surgery +RT \\
\hline HA07 & 60 & M & W & Frontal GBM (cross middle line) & Surgery + RT \\
\hline HA08 & 65 & $\mathrm{~F}$ & W & Multicentric GBM & Stereotactic biopsy + RT+ TMZ \\
\hline HA09 & 32 & $\mathrm{~F}$ & W & Multicentric GBM & $\begin{array}{l}\text { Stereotactic biopsy } \\
+\mathrm{RT}+\mathrm{TMZ}+\text { Nimotuzumab }\end{array}$ \\
\hline HA10 & 57 & $\mathrm{~F}$ & W & Anaplastic astrocytoma & Surgery + RT+Nimotuzumab \\
\hline HA12 & 40 & $\mathrm{~F}$ & W & GBM & Surgery + ChT +RT + Nimotuzumab \\
\hline
\end{tabular}

Abbreviations: NW: Non-white.

Table 3 Individual performance and clinical responses.

\begin{tabular}{|c|c|c|c|c|c|c|}
\hline Code & Initial KPS & $\begin{array}{c}\text { KPS after } 1 \text { month of } \\
\text { treatment }\end{array}$ & $\begin{array}{l}\text { Antitumor } \\
\text { response }\end{array}$ & Causes of deaths & $\begin{array}{l}\text { SV since diagnostic } \\
\text { (months) }\end{array}$ & $\begin{array}{c}\text { SV since start } \\
\text { of CIGB-128 } \\
\text { (months) }\end{array}$ \\
\hline HA01 & 20 & 50 & PR & Tumor progression & 7.6 & 5.3 \\
\hline HA03 & 20 & 0 & PR & Pulmonary thromboembolism & 1.2 & 1.0 \\
\hline $\mathrm{HAO4}$ & 40 & 70 & PR & Bronchopneumonia & 4.2 & 4.0 \\
\hline HA06 & 50 & 80 & $\mathrm{CR}$ & Pulmonary thromboembolism & 12.5 & 10.0 \\
\hline HA07 & 50 & 80 & PR & Pulmonary thromboembolism & 6.6 & 6.2 \\
\hline HA08 & 50 & 50 & CR & Tumorbleeding & 2.9 & 2.6 \\
\hline HA09 & 70 & 90 & $N R^{*}$ & Tumor progression & 6.1 & 5.6 \\
\hline HA12 & 60 & 70 & $N R^{*}$ & Tumor progression & 25.8 & 13.1 \\
\hline
\end{tabular}

Abbreviations: CR: Complete response; PR: Partial response; NR: No responses; * No evaluable patients (no final imagologicalevaluation available).

An independent central pathology review of all histology's was conducted by Dr. David Cubero, Pathology department, from "Hermanos Ameijeiras" Hospital (HAH), Havana. Patients had to show unequivocal evidence of progression by gadolinium ( $\mathrm{Gd}$ ) enhanced magnetic resonance imaging (MRI) or contrast-enhanced axial computed tomography $(\mathrm{CT})$.

The protocol written to harmonize the treatment of patients was approved by the Ethics Committee and the Scientific Review Board of the $\mathrm{HAH}$, in accordance with the ethical principles stated in the declaration of Helsinki.

All the patients were treated in the specialized rooms in the neurosurgery service ( 3 times a week) located in the hospital "Hermanos Ameijeiras", Havana, Cuba. Upon clinical improvement patients continued the treatment as outpatients.

\section{Protocol treatment}

CIGB-128 is stabilized pharmaceutical formulation containing co-lyophilized IFNs $-\alpha$ and $-\gamma$. Lyophilized CIGB-
128 was dissolved in $1-2 \mathrm{~mL}$ of water for injection and administered, 3 times a week for 1 month; intracranial (repeated punctures) using spaces after surgical craniotomy (where the bone is missing). The general schedule for administration was as fallowed: 1st week: 3.5 MIU CIGB128; 2nd and 3rd weeks: 7.0 MIU CIGB-128; 4th week: 14 MIU CIGB-128.

These regimens of treatment were repeated in some patients, with doses or administration frequency adjustments depending of adverse reactions and/or clinical response. Maintenance of treatment was left to the treating physician in correspondence with the clinical improvement or until unacceptable toxicity. Depending of treatment tolerance, the administered doses and/or their frequency were reduced to half. Clinical response that justified the treatment adjustments or its prolongation was based in tumor or edema volume reduction, and improvements in neurological behaviors.

Administration of growth factors to boost the absolute neutrophil counts was not employed. Prophylactic 
antiemetics were permitted as needed. Analgesics (oral dipyrone) at doses $600 \mathrm{mg}$ were administered every $6 \mathrm{~h}$ in the case of headache, fever or flu-like symptoms and adjustedifnecessary. Mannitolorfurosemidewasemployed in the cases of edema or intracranial hypertension. The electrolyte balance was corrected in the required cases. The intravenous steroids used were methylprednisolone or dexamethasone and as anticonvulsants, phenytoin and carbamazepine.

\section{Clinical evaluation}

All cases were examined weekly during the first weeks and monthly during the treatment and follow-up period after the end of treatment. The main efficacy evaluation variable was safety, evaluated by the occurrence of adverse events. Others variables were antitumoral response, performance status(KPS), muscular power (ASIA neurological assessment scale) and overall survival.

Objective tumor assessment was performed by $\mathrm{Gd}$ enhanced MRI according to a strictly defined protocol. MRI scanning was performed at trial entry within two weeks before first CIGB-128 treatment and every week during biotherapy. Copies of all scans were centrally reviewed at Radiology department of Ameijeiras hospital. The assessment of tumor response was based on criteria defined by RECIST [33] and carried out by the central reviewer using MRI scans neurologic evaluation, which was performed at each study visit, was based on changes in signs and symptoms from the previous examination.

Tumor response rates were based on the tumor area by measuring the diameter. It was categorized as complete response (CR): total disappearance of the tumor; partial response (PR): a clearly visible size reduction ( $\geq 30 \%)$; stable disease (SD): $<30 \%$ reduction in the tumor size; and progression $(P)$ defined as any relative increase in the lesion size ( $\geq 20 \%)$. The $C R$ responses were confirmed by computerized axial tomography and cytology. Patients without final imagological evaluation were considered nonevaluable, and non-responder to the treatment (intention to treat analysis). Patients were followed until dead.

The McDonald scale was not employed due to advanced state of diseases and the intense use of steroid in several patients.

Safety and tolerability were monitored by means of a rigorous adverse events control and their frequency calculated. During the treatment, patients were carefully monitored for side effects. Adverse events during treatment or up to 30 days after initiation of therapy were scored according to CTCAE v3.0. Additionally, blood samples were taken for routine hematological and biochemical determinations. Abnormal laboratory values were recorded as serious adverse events only if they caused hospitalization, transfusion of blood products or discontinuation of therapy.

\section{Laboratory procedures}

Hematological counts and blood chemistry were done according to usual clinical laboratory procedures, using advanced automated analyzers. These included hemoglobin, hematocrit, erythrocyte sedimentation rate (ESR), leukocytes and platelets counts, transaminases, bilirubin, creatinine and urea. Electrolyte quantification (sodium, potassium and chloride) was also recorded.

\section{Statistical analyses}

Quantitative variables were expressed as mean \pm standard deviation (SD) or median \pm interquartile range (IR); qualitative were given as absolute values and percentages. Influence of baseline and demographic variables on response was tested using univariate analyses by the chi-squared or Fisher's exact test and the odds ratio as association measure with the 95\% confidence interval (Cl) associated. The $95 \% \mathrm{Cl}$ were estimated for outcome variables. The product limit method of Kaplan-Meier was used to estimate the overall survival at six months with the $95 \%$ confidence intervals $(\mathrm{Cl})$. Safety variables were subjected to descriptive analysis. The benefit-risk ratio was estimated using the Bayes factor.

\section{Results}

\section{Patient characteristics}

From October 2006 to August 2008, at the HHA were selected 10 patients to be treated with CIGB-128 as a palliative treatment. Nine patients (90\%) had GBM and one patient AA (10\%) by clinical, histological (on central pathology review), and imagenollogy $T$ axial tomography and/or MRI. The safety population included all treated patients.

\section{Exposure to $C I G B-128$}

Seventy percent of patients interrupted the treatment, with death (40\%) as the most frequent causes of interruptions. Thirty percent of patients stopped the treatment before a month because local infection at surgery site (patient HHA03); death (patient HHA-05, apparently due to pulmonary thromboembolism); tumor progression (patient HHA-09) and seizures and pneumonia (patient HHA-12).

Fifty percent of patients received CIGB-128 during one month, 30\% maintained the treatment for more than one month and $20 \%$ prolonged the administration of CIGB-128 during 5 months. The mean treatment period was 48.3 days with administration of total dose between 10.5 and 152.5 MIU of IFN. 50\% of patients received 3.5 MIU dose per administration. Patients HHA-05, HHA-09 and HHA-12 received only 4, 3 and 9 CIGB-128 applications, respectivelly. Patients without final imagological evaluation (HHA-05 and HHA-12) were considered non-responder to the treatment (intention to treat analysis).

However, the following comments can be provided. Patients that received more than 12 applications of CIGB128 or more than 42 MIU of IFN had $100 \%$ favorable (CR or $\mathrm{PR}$ ) clinical response, while in patients received lower total doses or less amount of administered drug, the clinical response were $57 \%$ and $62 \%$ respectively.

\section{Adverse events}

The most common adverse events ( $\geq 10 \%)$, were fever (55.3\%), extrapyramidal reactions (15.8\%) hypopotassemia (13.2\%). The frequent adverse events $(\geq 1 \%)$, were as 
follows: depression (5.7\%), anorexia (5.3\%), and weight loss (5.3\%). The other detected adverse events were diarrhea (2.6\%), coagulopathies (5.3\%), and wound sepsis $(2.6 \%)$. $80 \%$ of patients presented fever, $50 \%$ hypopotassemia, $30 \%$ extrapyramidal reactions and anorexia, and 20\% depression and weight loss.

Hematologic toxicity occurred in a limited proportion of patients as thrombocytopenia observed in one patient (HHA-08) that caused the death of patient that was under temozolomide treatment. The lowering of potassium (hypopotassemia) was detected in 6 patients during the first week of treatment. Five of these patients presented normal levels (3.2-5.0 $\mathrm{mmol} / \mathrm{L})$ of potassium before treatment with CIGB-128 and one had levels under normal range. As the treatment prolonged the levels of potassium were recovered.

Less than $10 \%$ of patients had depression, anorexia, coagulopathies and loss body weight. Adverse events were mild or moderate and relieved spontaneously or with specific medication. Four sever adverse events were observed in two patients, one diarrhea, two coagulopathies and one wound sepsis.

The analysis of causality of adverse events identified the fever as definitive related to the treatment with CIGB128; extrapyramidal movements as very probably related; weight loss anorexia, and depression as related; and coagulopathies and wound sepsis as not related to the use of CIGB-128, respectively.

Two patients had severe adverse events, and one of them died (patient HA-09). The definitively interruption of the treatment was necessary only in patient HA-08 which received a total doses of $42 \mathrm{MIU}$. In patient $\mathrm{HA}-03$ that received total doses of $23 \mathrm{MIU}$, the temporal interruption of the treatment and the antibiotic therapy led to the resolution of adverse events. Ten patients died during the study. The death was not related to the treatment with CIGB-128. Table 4, shows the cause of death of patients.

Table 4 Analysis of deaths.

\begin{tabular}{|c|c|c|}
\hline Variable & & $N(\%)$ \\
\hline \multicolumn{3}{|l|}{ Dead } \\
\hline & Yes & $7(70 \%)$ \\
\hline & No & $3(30 \%)$ \\
\hline \multicolumn{3}{|l|}{ Causes of death } \\
\hline & Tumor progression & $4(22 \%)$ \\
\hline & $\begin{array}{l}\text { Pulmonary } \\
\text { Thromboembolism }\end{array}$ & $4(44 \%)$ \\
\hline & Bronchopneumonia & $1(10 \%)$ \\
\hline & Bleeding & $1(11 \%)$ \\
\hline \multicolumn{3}{|l|}{ Gliomas } \\
\hline $\begin{array}{l}\text { Overall survival from } \\
\text { diagnosis (months) }\end{array}$ & Mean \pm DS (IC 95\%) & $34 \pm 14(6.2 ; 62)$ \\
\hline $\begin{array}{l}\text { Overall survival from the } \\
\text { beginning of treatment } \\
\text { (months) }\end{array}$ & Mean \pm DS (IC 95\%) & $9.5 \pm 3.3(3.0 ; 16)$ \\
\hline
\end{tabular}

\section{Clinical improvements}

Three out of 10 treated subjects showed absence of tumor cells in the tumor niche by histology that resembles a clinical situation of complete response. Four patients presented partial responses. Three patients were non-responder (no evaluable patients) and one with tumor progression.

Mean survival from the diagnostic and from the beginning of CIGB-128 treatment were determined. The six-month survival rate was $20 \%$ with a mean overall survival of 34 months (Figure 1). The $100 \%$ of patients died and the most frequent causes of death were pulmonary thromboembolism (40.0\%), tumor progression (40.0\%), bronchopneumonia (10.0\%) and bleeding (10\%).

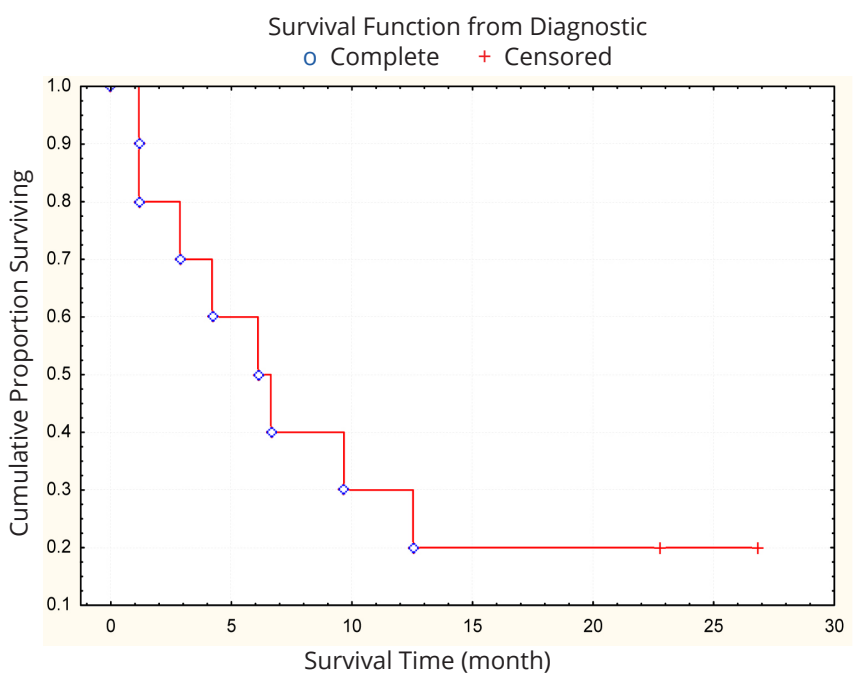

Figure 1 Kaplan-Meier estimates of overall survival of patients treated with CIGB-128.

\section{Quality of life}

KPS after one month of treatment showed improvement in 8 patients (66.6\%). Four patients with KPS 50-70 improved to KPS 80-100 and four from KPS 0-40 improved to KPS 50-70. Two patients showed stabilization of KPS and one deteriorated his performance status. Improvements were also noted in Asia Scale in some patients. After one month of treatment with CIGB-128, five patients improved Asia Scale, 1 was stable, and 1 get worse.

\section{Discussion}

The IFNs produce several side effects (flu-like symptoms) when administered to patients. The most frequent was the fever. The observed events are similar as reported for IFNs [34, 35] and in previous studies with CIGB-128 [29]. Other frequent events were extrapyramidal movements and hypopotassemia.

The fever is very common during the treatment with IFNs. The mechanisms of fever induction by these 2 types of interferons may be different. IFN-alpha has been shown to be intrinsically pyrogenic with its action possibly mediated by prostaglandin E2 production in the hypothalamus [36]. While the mechanisms of fever induction by IFN gamma have not been studied directly, recent evidence suggests that administration of this lymphokine stimulates release of other lymphokines, such as interieukin-1 and interleukin-2 [37], which could be responsible for some of 
the clinical biological activity of IFN gamma; i.e., release of interleukin-1, an endogenous pyrogen [38], may account for the fever.

Hypopotassemiais an uncommon side effect reported during the use of IFNs. IFN- $\alpha$ and IFN- $\gamma$ increase the expression of aquaporin that control water flux to inside the cells [39-42] and could contributed to electrolytic disbalance in the patients treated withCIGB-128. Another possible cause of hypopotassemia could be the drugs used to control the edema as mannitol and furosemide. Additionally, when blood-brain barrier is disrupted, the vascular regulation is affected, and may occur the release of free radicals and $\mathrm{K}+, \mathrm{Fe}++, \mathrm{Cu}++$, that disturb the metabolism [42]. Mild hypopotassemia was observed in six patients, all under anti-edema treatment.

The extrapyramidal symptoms were observed in 3 patients at the end of third week of intratumoral administration and coincident with the increased doses of treatment and relieved after lowering the doses. Sporadic cases of this reaction associated to IFNs have been described [43]. Apparently these reactions were associated to the CIGB128 treatment, but we cannot discard other causes related directly to frontal and/or deep brain tumors [44, 45].

The extrapyramidal symptoms were observed in patients with negative cytology from tumor biopsies, as detected in patient $\mathrm{HA}-06, \mathrm{HA}-07$, and $\mathrm{HA}-01$. In the case of patient HA-01, is important to note that the treated lesion, after reduction of tumor volume, was totally resected with no recurrence after 6 months of surgery. It could be possible that the extrapyramidal reactions appeared as consequences of treatment toxicity over healthy tissue.

Anorexia and diarrhea (gastrointestinal events) are rare in patients with brain tumors treated with IFNs $[46,47]$. During the use of 9-10 MIU of IFN 3 time a week, with cumulative doses ranging from 113-160 MIU, were observed acute adverse events as fever, vomiting and headache. Fatigue, loss of appetite, loss of weight, and hematological toxicity occurred, independently of doses of treatment [48]. Coagulopathy was observed in one patient, which was associated to the use of temozolomide.

CIGB-128 was well tolerated. The adverse events were mainly mild, with favorable evolution, in several cases without the application of any therapy. Severe adverse events were detected only in two patients (one diarrhoea, two coagulopathies and one wound sepsis), and were not related to the CIGB-128. The extrapyramidal movements disappeared with the doses reduction in these patients.

The absence of tumor cells in 3 out of 10 treated subjects, and the fact that only one patient showed tumor progression is a clear evidence of the expected antitumoral potency of the combination.

The IFN- $\alpha$ treatment of patients with malignant gliomas showed positive results in some clinical trials [49-51] but not in others $[52,53]$. The results from the use of IFN- $\gamma$ in these kinds of patients were expected with interest, because the immune-suppression is one of the principal characteristics of these patients. However, no differences in survival of patients were observed [54,55]. The employment of IFN $-\beta$ in the treatment of patients with malignant gliomas resulted more encouraging [56, 57]. However, a large phase III trial compared post-radiation BCNU either with or without IFN- $\alpha$, and did not show a benefit with the addition of IFN- $\alpha$ [58].

The combination of IFN- $\alpha$ and IFN- $\gamma$ has not been reported in the treatment of patients with malignant brain tumor. However, the use of CIGB-128 has showed encouraging results in the treatment of skin tumors, with more number of complete responses than separated IFNs $[29,59]$. The pharmacodynamics of CIGB-128 in patients with mycosis fungoides revealed higher blood levels of several IFN response markers with respect to observed in similar studies with separated IFNs or even pegylated IFN- $\alpha$ [60].

In this report of patients with low KPS, bearing malignant gliomas, the objective response to CIGB-128 demonstrated, for the first time, the anti-malignant glioma activity of the combination of both, IFN- $\alpha$ and IFN- $\gamma$. A mean overall survival of 34 months, are comparable to results reported in the literature for various combination regimens.

Factors that are prognostic for survival, apart from treatment modalities, are patient age, performance status and degree of surgical resection [61]. Taking in account that the patients in this report had very low life expectancy, with disease progression, the results are very encouraging, even when comparing with studies of temozolomide and procarbazine at first recurrence in patients with GBM that reported median progression-free survivals of 9 to 12 weeks and overall survival times of 23 to 29 weeks after chemotherapy were initiated [62].

The absence of tumor cells in 3 out of 10 treated subjects, and the fact that only one patient showed tumor progression is a clear evidence of the expected antitumoral potency of the combination. As reviewed in the introduction, the anti-proliferative, anti-angiogenic and potential terminal differentiation of GICs, are properties of both IFNs that may contribute to more potent effect in the control of malignant gliomas.

If IFNs are acting as a cytostatic rather than a cytotoxic agent, one might expect to see a prolongation of regression and survival rather than an increase in the proportion of patients experiencing tumor regression. Malignant gliomas are characterized by rapid cell proliferation activity, high invasiveness into the surrounding brain, and increased degree of vascularity [63]. Tumor-related angiogenesis contributes significantly to the malignant phenotype of tumors. Inhibiting the sprouting of new capillaries from preexisting blood vessels is one of the most promising therapeutic approaches for gliomas. CIGB128 has demonstrated inhibition of proangiogenic factors produced likely by tumor cells in a nude mice model of malignant glioma using U87MG cell line (un-published from our laboratory).

Nevertheless, response rates in patients with recurrent GBM are low and of short duration with most patients 
achieving temporary disease stabilization. A review of the literature suggested that an agent demonstrating a sixmonth progression-free survival of $10 \%$ or greater would be considered active $[64,65]$.

\section{Quality of life}

The improvement of quality of life is a relevant finding of this study. Performance status (66\%) and ASIA (50\%) scale showed improvements in treated patients. Similar effects were observed in patients with malignant gliomas treated with temozolomide [66]. Another interesting finding probably influenced the quality of life of patients, was the reduction of intracranial edema after the first administrations of CIGB-128. This observation is in correspondence with anti-edema edema effects observed in patients with malignant gliomas treated with antiangiogenic therapies $[67,68]$.

The limitations of this study are related to the small group of patients evaluated, without any previous design. However, the result evidenced that CIGB-128 is safe and biologically active therapy, with good perspective for the treatment of malignant gliomas.

The multicenter clinical trial, MAGINC study (Cuban Clinical Trial Public Register: RPCEC00000120),with intracranial administration using Ommaya reservoir was started in patients with recurrent malign glioma, however, stopped due to the complexity of this way of administration. Intravenous route is being explored in a phase I multicenter study, BRATINC (RPCEC00000140).

\section{Conclusions}

The results presented suggest that the CIGB-128 is safety and potential effective approach for the treatment of human malignant gliomas. The results of this study showed unique data for IFN alpha2b and gamma combination application in patients with advanced malignant brain tumors. The data presented support the locoregional IFN delivery as an affordable therapeutic approach for these non-curable tumors. Further, controlled clinical trials are encouraged to confirm this assessment.

\section{Competing interests}

Authors YGV, EGI and IBR are employees of the Center for Genetic Engineering and Biotechnology, Havana network, where the synergistic formulation of IFNs- $\alpha$ and $-\gamma$ is produced. The rest of the authors have nocompeting interests at all.

\section{List of abbreviations}

CIGB: Center for Genetic Engineering and Biotechnology; IFN: Interferon; MIU: Million international units; OR: Overall response; PR: Partial response; P: Progression; SD: Stable disease.

\section{References}

[1] Lens MB, Dawes M. Interferon alfa therapy for malignant Melanoma: a systematic review of randomized controlled trials. J ClinOncol. 2002; 20(7):1818-1825.
[2] Horton HM, Anderson D, Hernandez P, Barnhart KM, Norman JA, et al. A gene therapy for cancer using intramuscular injection of plasmid DNA encoding interferon $\alpha$. Proc Natl Acad Sci USA. 1999; 96(4):15531558.

[3] Roth W, Wagenknecht B, Dichgans J, Weller M. Interferon-alpha enhances CD95L-induced apoptosis of human malignant glioma cells. Journal of neuroimmunology. 1998; 87(1-2):121-129.

[4] Son MJ, Song HS, Kim MH, Kim JT, Kang CM, et al. Synergistic effect and condition of pegylated interferon alpha with paclitaxel on glioblastoma. Int J Oncol. 2006; 28(6):1385-1392.

[5] Tjuvajev J, Gansbacher B, Desai R, Beattie B, Kaplitt M, et al. RG-2 glioma growth attenuation and severe brain edema caused by local production of interleukin-2 and interferon- gamma. Cancer Res. 1995; 55(9):1902-1910.

[6] Visse E, Siesjö P, Widegren B, Sjögren HO. Regression of intracerebral rat gliomaisografts by therapeutic subcutaneous immunization with interferon-gamma, interleukin-7, or B7-1-transfected tumor cells. Cancer Gene Ther. 1999; 6(1):37-44.

[7] Choi C, Jeong E, Benveniste EN. Caspase-1 mediates Fas-induced apoptosis and is up-regulated by interferon-gamma in human astrocytoma cells. J Neurooncol. 2004; 67(1-2):167-176.

[8] Zhang R, Banik NL, Ray SK. Combination of all-trans retinoic acid and interferon-gamma suppressed PI3k/Akt survival pathway in glioblastoma T98g cells whereas NF-kappaB survival signaling in glioblastoma U87mg cells for induction of apoptosis. Neurochem Res. 2007; 32(12):2194-21202.

[9] Zhang R, Banik NL, Ray SK. Combination of all-trans retinoic acid and interferon-gamma upregulated p27 (kip1) and down regulated CDK2 to cause cell cycle arrest leading to differentiation and apoptosis in human glioblastoma LN18 (PTEN-proficient) and U87MG (PTENdeficient) cells. Cancer Chemother Pharmacol. 2008; 62(3):407-416.

[10] Qin Z, Blankenstein T. CD4+ T cell-mediated tumor rejection involves inhibition of angiogenesis that is dependent on IFN gamma receptor expression by nonhematopoietic cells. Immunity. 2000; 12(6):677686.

[11] Hayakawa $\mathrm{Y}$, Takeda K, Yagita H, Smyth MJ, Van Kaer L, et al. IFN- $\gamma$ mediated inhibition of tumor angiogenesis by natural killer T-cell ligand, alpha-galactosylceramide. Blood. 2002; 100(5):1728-1733.

[12] Angiolillo AL, Sgadari C, Tosato $G$. A role for the interferon-inducible protein 10 in inhibition of angiogenesis by interleukin-12. Ann N Y Acad Sci. 1996; 795:158-167.

[13] Battle TE, Lynch RA, Frank DA. Signal transducer and activator of transcription 1 activation in endothelial cells is a negative regulator of angiogenesis. Cancer Res. 2006; 66(7):3649-3657.

[14] Ehtesham M, Samoto K, Kabos P, Acosta FL, Gutierrez MAR, et al. Treatment of intracranial glioma with in situ interferon - gamma and tumor necrosis factor-alpha gene transfer. Cancer Gene Ther. 2002; 9(11):925-934.

[15] Yuki K, Natsume A, Yokoyama H, Kondo Y, Ohno M, et al. Induction of oligodendrogenesis in glioblastoma-initiating cells by IFN-mediated activation of STAT3 signaling. Cancer Lett. 2009; 284(1):71-79.

[16] Stupp R, Mason WP, den Bent MJ, Weller M, Fisher B, et al. Radiotherapy plus concomitant and adjuvant temozolomide for glioblastoma. N Engl J Med. 2005; 352(10):987-996.

[17] Wen PY, Kesari S. Malignant gliomas in adults. N Engl J Med. 2008; 359(5):492-507.

[18] Keime-Guibert F, Chinot O, Taillandier L, Cartalat-Carel S, Frenay M, et al. Radiotherapy for glioblastoma in the elderly. N Engl J Med. 2007; 356(15):1527-1535.

[19] Wakabayashi T, Kayama T, Nishikawa R, Takahashi H, Yoshimine T, et al. A multicenter phase I trial of interferon-beta and temozolomide combination therapy for high-grade gliomas (INTEGRA Study). Jpn J Clin Oncol. 2008; 38(10):715-718.

[20] Kang MK, Kang SK. Tumorigenesis of chemotherapeutic drug-resistant cancer stem-like cells in brain glioma. Stem Cells Dev. 2007; 16(5):837847.

[21] Fu J, Liu ZG, Liu XM, Chen FR, Shi HL, et al. Glioblastoma stem cells resistant to temozolomide-induced autophagy. Chinese Med J. 2009; 122(11):1255-1259.

[22] Maher EA, Furnari FB, Bachoo RM, Rowitch DH, Louis DN, et al. Malignant glioma: genetics and biology of a grave matter. Genes Dev. 2001; 15(11):1311-1333.

[23] Wesseling P, Ruiter DJ, Burger PC. Angiogenesis in brain tumors; pathobiological and clinical aspects. J Neurooncol. 1997; 32(3):253265.

[24] Desbaillets I, Diserens AC, De Tribolet N, Hamou MF, Van Meir EG. Regulation of interleukin-8 expression by reduced oxygen pressure in human glioblastoma. Oncogene 1999; 18(7):1447-1456. 
[25] Salmaggi A, Eoli M, Frigerio S, Silvani A, Gelati M, et al. Intracavitary VEGF, bFGF, IL-8, IL-12 levels in primary and recurrent malignant glioma. J Neurooncol. 2003; 62(3):297-303.

[26] FDA. Avastin Approval History. U.S. Food and Drug Administration. 2004. (Website)

[27] Vredenburgh JJ, Desjardins A, Herndon JE 2nd, Dowell JM, Reardon $\mathrm{DA}$, et al. Phase II trial of bevacizumab and irinotecan in recurrent malignant glioma. Clin Cancer Res. 2007; 13(4):1253-1259.

[28] Vredenburgh J, Desjardins A, Herndon JE, Marcello J, Reardon DA, et al. Bevacizumab plus irinotecan in recurrent glioblastoma multiforme. J Clin Oncol. 2007; 25(30):4722-4729.

[29] Anasagasti-Angulo L, García-Vega Y, Barcelona-Perez S, Lopez-Saura P, Bello-Rivero I. Treatment of advanced, recurrent, resistant to previous treatments basal and squamous cell skin carcinomas with a synergistic formulation of interferons. Open, prospective study. BMC Cancer. 2009; 9:262.

[30] Levy DE, Lew DJ, Decker T, Kessler DS, Darnell JE Jr. Synergistic interaction between interferon-alpha and interferon-gamma through induced synthesis of one subunit of the transcription factor ISGF3. EMBO J. 1990; 9(4):1105-1111.

[31] Ehtesham M, Stevenson CB, Thompson RC. Stem cell therapies for malignant glioma. Neurosurg Focus. 2005; 19(3):E5.

[32] Louis DN, Ohgaki H, Wiestler OD, Cavenee WK, Burger PC, et al. The 2007 WHO classification of tumours of the central nervous system. Acta Neuropathol. 2007; 114(2):97-109.

[33] Therasse P, Arbuck SG, Eisenhauer EA, Wanders ], Kaplan RS, et al. New Guidelines to Evaluate the Response to Treatment in Solid Tumors. J Natl Cancer Inst. 2000; 92(3):205-216.

[34] Gutterman JU, Rosenblum MG, Rios A, Fritsche HA, Quesada JR. Pharmacokinetic study of partially pure gamma-interferon in cancer patients. Cancer Res. 1984; 44(9):4164-4171.

[35] GuttermanJU, Fein S, QuesadaJ, Homing SJ, LevineJF, et al. Recombinant leukocyte A interferon: pharmacokinetics, single-dose tolerance, and biologic effects in cancer patients. Ann Intern Med. 1982; 96(5):549556.

[36] Vial T, Descotes J. Clinical toxicity of the interferons. Drug safety. 1994; 10(2):115-150.

[37] Vilcek J, Gray PW, Rinderknecht E, Sevastopoulos CG. Interferon gamma: a lymphokine for all seasons. In: E. Pick (ed.), Lymphokines. Orlando: Academic Press. Inc. 1984.

[38] Duff GW, Durum SK. The pyrogenic and mitogenic actions of interleukin-1 are related. Nature. 1983; 304(5925):449-451.

[39] Smith JK, Siddiqui AA, Modica LA, Dykes R, Simmons C, et al. Interferonalpha upregulates gene expression of aquaporin- 5 in human parotid glands. J Interferon Cytokine Res. 1999; 19(8):929-935.

[40] Satoh J, Tabunoki H, Yamamura T, Arima K, Konno H. Human astrocytes express aquaporin-1 and aquaporin-4 in vitro and in vivo. Neuropathology. 2007; 27(3):245-256.

[41] Bravo DL, Marhuenda RE. Manual de Fármacoterapia. Serie Farmacia actual. Farmacia actual. 2005; Elsevier España.

[42] Beers M. The Merck Manual of Health and Aging. Problems with electrolyte balance, Section 3: Medical conditions and chapter 18, water and electrolyte balance.

[43] Bersano A, Aghemo A, Rumi MG, Ballabio E, Candelise L, et al. Recovery after L-DOPA treatment in peginterferon and ribavirin induced parkinsonism. Eur J Intern Med. 2008; 19(5):370-371.

[44] Polyzoidis KS, McQueen JD, Rajput AH, Mac-Fadyn DJ. Parkinsonism as a manifestation of brain tumour. Surg Neurol. 1985; 23(1):59-63.

[45] Wood N, Pall HS, Williams AC, Dieppe C. Extrapyramidal reactions to anti-inflammatory drugs. J. Neurol Neurosurg Psychiatry. 1988; 51(5):731-732.

[46] Olson JJ, James CD, Lawson D, Hunter S, Tang G, et al. Correlation of the response of recurrent malignant gliomas treated with interferon alpha with tumor interferon alpha gene content. Int J Oncol. 2004; 25(2):419-427.

[47] Chang SM, Barker FG, Huhn SL, Nicholas MK, Page M, et al. High dose oral tamoxifen and subcutaneous interferon alpha-2a for recurrent glioma. Journal of neuro-oncology. 1998; 37(2):169-176.

[48] Obbens EA, Feun LG, Leavens ME, Savaraj N, Stewart DJ, et al. Phase I clinical trial of intralesional or intraventricular leukocyte interferon for intracranial malignancies. J Neuroncol. 1985; 3(1):61-67.

[49] Jereb B, Petric J, Lamovec J, Skrbec M, Soss E. Intratumor application of human leukocyte interferon- alpha in patients with malignant brain tumors. Am J ClinOncol. 1989; 12(1):1-7.

[50] Buckner JC, Brown LD, Kugler JW, Cascino TL, Krook JE, et al. Phase II evaluation of recombinant interferon alpha and BCNU in recurrent glioma. J Neurosurg. 1995; 82(3):430-435.
[51] Dillman, RO, Wiemann M, Oldham RK, Soori G, Bury M, et al. Interferon alpha-2a and external beam radiotherapy in the initial management of patients with glioma: a pilot study of the national biotherapy study group. Cancer Biother. 1995; 10(4):265-271.

[52] Martínez R, Vaquero J, Ramiro J, García Salazar F, De Oya S. Intratumora and Intraventricular Human Lymphoblastoid Alphalnterferon (HLBI) for treatment of Glioblastoma multiforme. Acta Neurochir. 1989; 100(1-2):46-49.

[53] Vaquero J, Martínez R, Ramiro J, Salazar GF, Barbolla L, et al. Immunotherapy of Glioblastoma with Intratumoral administration of autologous Lymphocytes and human Lymphoblastoid Interferon. A further clinical Study. Acta Neurochir. 1991; 109:42-45.

[54] Farkkila M, Jaaskelainen J, Kallio M, Blomstedt G, Raininko R, et al. Randomised, controlled study of intratumoral recombinant gammainterferon treatment in newly diagnosed glioblastoma. Br J Cancer. 1994; 70(1):138-141.

[55] WolfJE, Warner S, Reinert C, Gnekow A, Fortmann RD, et al. Maintenance treatment with interferon-gamma and low-dose cyclophosphamide for pediatric high- grade glioma. J neurooncol. 2006; 79(3):315-321.

[56] Fine HA, Wen PY, Robertson M, O'Neill A, Kowal J, et al. A phase I trial of a new recombinant human beta-interferon (BG9015) for the treat-ment of patients with recurrent gliomas. Clin Cancer Res. 1997; 3(3):381-387.

[57] Yung WK, Prados N, Levin VA, Fetell MR, Bennett J, et al. Intravenous recombinant interferon-b in patients with recurrent malignant gliomas: a phase I/II study. J ClinOncol. 1991; 9(11):1945-1949.

[58] Buckner JC, Schomberg PJ, McGinnis WL, Cascino TL, Scheithauer BW, et al. A phase III study of radiation therapy plus carmustine with or without recombinant interferon-alpha in the treatment of patients with newly diagnosed high-grade glioma. Cancer. 2001; 92(2):420-433.

[59] Bello-Rivero I, Garcia-Vega Y, Valenzuela-Silva C, Bello-Alvarez C, Vázquez-Blomquist $D$, et al. Development of a new formulation of interferons (HEBERPAG) for BCC treatment. J Cancer Res Ther. 2013; 1(10):235-243.

[60] García-Vega Y, García-García I, Collazo-Caballero S, Santely-Pravia E, Cruz-Ramírez A, et al. Pharmacokinetic and pharmacodynamics characterization of a new formulation containing synergistic proportions of interferons alpha-2b and gamma (HeberPAG) in patients with mycosis fungoides: an open-label trial. BMC Pharmacology and Toxicology. 2012; 13:20.

[61] Van Genugten JA, Leffer P, Baumert BG, Tjon-A-Fat H, Twijnstra A. Effectiveness of temozolomide for primary glioblastoma multiforme in routine clinical practice. J Neurooncol. 2010; 96(2):249-257.

[62] Brada M, Hoang-Xuan K, Rampling R, Dietrich PY, Dirix LY, et al. Multicenter phase II trial of temozolomide in patients with glioblastoma multiforme at first relapse. Ann Oncol. 2001; 12(2):259-266.

[63] Hong YK, Chung DS, Joe YA, Yang YJ, Kim KM, et al. Efficient inhibition of in vivo human malignant glioma growth and angiogenesis by interferonbeta treatment at early stage of tumor development. Clinical Cancer Research. 2000; 6(8):3354-3360.

[64] Hosli P, Sappino AP, de Tnbolet N, Dietrich PY. Malignant glioma: Should chemotherapy be overthrown by experimental treatments $\square$ Ann Oncol. 1998; 9(6):589-600.

[65] Pech IV, Peterson K, Cairncross JG. Chemotherapy for brain tumors. Oncology. 1998; 12(4):537-543.

[66] Osoba D, Brada M, Yung WK, Prados M. Health-related quality of life in patients treated with temozolomide versus procarbazine for recurrent glioblastoma multiforme. J Clinic Oncol. 2000; 18(7):1481-1491.

[67] Pope WB, Lai A, Nghiemphu P, Mischel P, Cloughesy TF. MRI in patients with high grade gliomas treated with bevacizumab and chemotherapy. Neurology. 2006; 66(8):1258-1260.

[68] Vredenburgh JJ, Desjardins A, Herndon JE, Quinn J, Rich J, et al. Bevacizumab, a monoclonal antibody to vascular endothelial growth factor (VEGF), and irinotecan for treatment of malignant gliomas. J Clin Oncol. 2006; 24(Suppl 18):1506. 